\title{
A composição legislativa na composição da personalidade humana
}

\author{
The legislative composition in the composition of human personality
}

Dirceu Pereira Siqueira*

Maria Luiza de Souza Rocha ${ }^{* *}$

Rodrigo Ichikawa Claro Silva****

\section{REFERÊNCIA}

SIQUEIRA, Dirceu Pereira; ROCHA, Maria Luiza de Souza; SILVA, Rodrigo Ichikawa Claro. A composição legislativa na composição da personalidade humana. Revista da Faculdade de Direito da UFRGS, Porto Alegre, n. 41, p. 226-250, dez. 2019. DOI: 〈https://doi.org/10.22456/0104-6594.84003 >.

\begin{abstract}
RESUMO
Pauta-se por reflexões circundantes a determinados princípios e valores que alicerçam ordenamentos pretensamente promovedores da pessoa humana como eixo vital de proteção e fomento, em consonância com a efetivação de direitos, em especial aqueles primordiais ao núcleo medular da personalidade e dignidade humana, na contraposição de aspectos e influências que derruem a legitimidade social de certas escolhas políticas eivadas de intenções particulares antagônicas ao melhor interesse público. Visa promover certa conscientização pela necessidade de (re)consideração de determinadas atuações político-sociais, notadamente no âmbito legislativo, para que sejam debelados obstáculos os quais se opõem ao reconhecimento e à real participação de cada pessoa na formação de elementos garantidores do livre desenvolvimento da personalidade e de uma vivência digna a todos. No que concerne ao aspecto metodológico desenvolve-se este trabalho, principalmente, pelo método dedutivo, através de pesquisa bibliográfica em escritos componentes do direito, rumo à formulação de considerações pretensamente conclusivas acerca da temática posta ao debate.
\end{abstract}

\section{PALAVRAS-CHAVE}

Direitos fundamentais. Pluralismo. Desenvolvimento da personalidade. Dignidade humana.

\begin{abstract}
It is guided by reflections surrounding certain principles and values that underpin laws that are supposed to promote the human person as a vital axis of protection and promotion, in line with the realization of rights, especially those primordial to the core core of personality and human dignity, in contrast of aspects and influences that overturn the social legitimacy of certain political choices and of private intentions antagonistic to the best public interest. It aims to promote a certain awareness of the need to (re) consider certain political and social actions, especially in the legislative sphere, so that obstacles are overcome, which oppose the
\end{abstract}

\footnotetext{
Coordenador e Professor Permanente do Programa de Doutorado e Mestrado em Direito do Centro Universitário Cesumar (UniCesumar); Pós-doutor em Direito pela Faculdade de Direito da Universidade de Coimbra (Portugal), Doutor e Mestre em Direito Constitucional pela Instituição Toledo de Ensino - ITE/Bauru, Especialista Lato Sensu em Direito Civil e Processual Civil pelo Centro Universitário de Rio Preto, Pesquisador Bolsista - Modalidade Produtividade em Pesquisa para Doutor - PPD - do Instituto Cesumar de Ciência, Tecnologia e Inovação (ICETI), Professor nos cursos de graduação em direito da Universidade de Araraquara (UNIARA), do Centro Universitário Unifafibe (UNIFAFIBE) e do Centro Universitário da Fundação Educacional de Barretos (UNIFEB), Professor Convidado do Programa de Mestrado em Master Of Science in Administrative Studies (MSAS)", Consultor Jurídico, Parecerista, Editor da REVISTA DIREITOS SOCIAIS E POLÍTICAS PÚBLICAS (QUALIS B1), Advogado.

** Mestranda no Programa de Pós-Graduação em Ciências Jurídicas (PPGCJ), pelo Centro Universitário de Maringá

(UniCesumar); Bolsista PROSUP/CAPES; Advogada. Maringá (PR), Brasil

*** Mestrando Programa de Pós-Graduação em Ciências Jurídicas (PPGCJ), pelo Centro Universitário Cesumar (UniCesumar); Bolsista PROSUP/CAPES. Maringá (PR), Brasil.
} 
recognition and real participation of each person in the formation of elements guaranteeing the free development of personality and a worthy experience to all. As far as the methodological aspect is concerned, this work is developed mainly by the deductive method, through bibliographical research in written components of the law, towards the formulation of supposedly conclusive considerations about the subject matter under debate.

\section{KEYWORDS}

Fundamental rights. Pluralism. Personality development. Human dignity.

\section{SUMÁRIO}

1. Introdução. 2. Critérios objetivos e igualdade de participação. 3. Legislação e pretensões evidenciadas. 3.1 Legitimidade de ação. 4 Influência na formação e desenvolvimento da pessoa no âmbito social. 5. Conclusão. Referências. Dados da publicação.

\section{INTRODUÇÃO}

Com a soma dos valores, fundamentos e princípios atinentes ao Estado, em consagração interna ou internacional, torna-se indeclinável que este haja de cumprir suas funções à via de reduzir desigualdades e exclusões sociais, em prol da dignidade humana, assegurando a todos, em condições reais de igualdade, o efetivo exercício de direitos vitais, notadamente aqueles tão caros à formação da própria personalidade e ao experimento de uma vivência digna. Ressaltado também que, a garantia contra a sucumbência da personalidade passa por viabilizar-se a afirmação da pessoa como tal, na perspectiva de poder atuar livremente, em acordo para com sua consciência, dentro dos limites legais e sociais pluralmente compostos.

Tanto mais autêntica e regular se mostra a atuação estatal quanto alcançado verdadeiro empoderamento de todos indivíduos que compõem sua estrutura, a viabilizar assim o assentamento dos múltiplos interesses demandados, desde que não se viole a ordem e os valores, nem indevidamente ultrapasse as possibilidades do Estado. Pois, as ações governamentais, nas esferas de todos os poderes, devem corresponder, na maior medida possível e dentro de determinado espaço temporal e cultural, à realidade social de cada grupo, segundo princípios de justiça e dignidade.

Entretanto, e infelizmente, muitas realidades são ainda marcadas por múltiplos vieses da exclusão, a exemplo das carências por suprimentos vitais, inefetividade de direitos, aumento da discriminação e estigmas, desaculturação, negativa de vínculos, entre outros que obstam a devida inclusão e reconhecimento do indivíduo, bem como a desejada transformação social para eventual alcance dos patamares teórica e positivamente inscritos em mandamentos. Ressalta-se, assim, que das crises sociais emanam também crises institucionais, acometidas pela ilegitimidade de determinadas facetas do exercício e dos 
objetivos do poder investido, principalmente enquanto analisada a não correspondência entre a representatividade e os fatores reais do poder para com certas demandas sociais.

Nada obstante, parece não se poder absolutamente estear todas mazelas sociais na atividade estatizada, mas há de se propiciar um suficiente complexo estrutural de fornecimento do suporte hábil para nulificar-se violações ou discrepâncias prejudiciais à efetivação de direitos e garantias cruciais, por uma condizente regulação, e não total substituição, das relações pessoais pluralmente projetadas no seio social, observado que, também a própria sociedade há de cumprir com a essência da ordem social para, por atuação própria, servir ao alcance de uma desejada extirpação das circunstâncias que afrontam a dignidade humana. Neste ponto também se há de questionar limites ao cômputo do direito como elemento de conserto à justa distribuição de bens ou oportunidades, em anexo aos planejamentos políticos.

De toda forma, a realidade social deve ser tida como o impulsor que valida a atuação do Poder Público, ao passo que este não pode desconsiderar as consequências e resultados práticos de suas políticas na efetiva realização dos anseios sociais legítimos. Deve então absorver as características distintivas do contexto político-social no qual investido, para adequadamente projetar a composição dos multifários ideais políticos e sociais em consonância com os valores e princípios assentados, na função de realizar uma digna vivência (co)existencial a, e por, todos.

Ainda, independentemente da técnica adotada, enfocados aqui os instrumentos da representação e da decisão por maioria, não cabe uma pretensa padronização ou a requisição de determinados patamares de formação ou posicionamento para que se possa influir nas decisões governamentais, sob pena de formar-se assim uma gestão elitista que não reflete a realidade social legitimadora do comando governante. Outrossim, justamente na pluralidade e vastidão de componentes, bem como na viabilização de mecanismos institucionalmente apropriados à legítima negociação formadora de acordos plurilaterais que melhor atendam o interesse coletivo, é que se valida e sustém o próprio poder e ofício público.

Mas, enfim, tendo em vista que o desprovimento de padrões elementares de educação e formação humana prejudicialmente limita a autonomia e capacidade de o indivíduo comensurar o cenário posto, para racionalmente participar de forma ativa e decisiva do processo estruturador, torna-se cada vez mais imperativa a busca por maior inclusão e aprimoramento de todos, em prol da mais digna atuação e desenvolvimento coletivo. 


\title{
2 CRITÉRIOS OBJETIVOS E IGUALDADE DE PARTICIPAÇÃO
}

Num plano ideário, a todos devem ser estabelecidas equânimes posições e capacidades viabilizadoras do cumprimento, com êxito, de seus próprios planos de vida, em forma livre e digna. Para tanto, fazem-se necessários mecanismos de igualação e inclusão que garantam uma efetiva participação ativa bem como a neutra atuação estatal ${ }^{1}$. Nesta diretriz, Jürgen Habermas anota que: "em nosso contexto, interessam sobretudo dois recursos de neutralização normativa das diferenças: (a) a garantia da coexistência em igualdade de direitos e (b) o asseguramento da legitimação mediante procedimentos"2.

Isto pois, mantém-se a instância de uma necessária institucionalização das demandas que rotineiramente se apresentam, bem como a justa mediação dos múltiplos interesses, por meio de procedimentos transparentes e objetivos, sobretudo o acesso às vias de participação e influência popular nas decisões centrais. Ademais, imprescindível a garantia de elementos fundamentais, em especial no que tange ao empoderamento individual e coletivo, para um conscientemente livre e efetivo exercício participativo do processo político e do diálogo compositivo no espaço público ${ }^{3}$.

Até porque, legítimo se configura o ordenamento jurídico e social estruturado por um conjunto de comunidades plural e igualitariamente contratantes entre si, com equilíbrio de forças e interesses, em prol do bem comum, por meio de normas gerais e realmente impessoais que dignifiquem o ser humano, sob pena de, assim não operando, derruir-se também a própria higidez social. No mesmo raciocínio, complementa-se com os dizeres de Alinne Cardim Alves e Cassiane de Melo Fernandes que:

\begin{abstract}
As escolhas para a concretização das normas constitucionais, em especial de direitos fundamentais, se apoiam no princípio democrático, em especial no que se refere ao pluralismo político, em que as escolhas devem ser pautadas por debates políticos e a população tenha abertura para se manifestar ${ }^{4}$.
\end{abstract}

\footnotetext{
${ }^{1}$ Em complemento, a seguinte constatação feita por Ana Paula de Barcellos: Ora, a consequência direta desses pressupostos - a igualdade e o caráter democrático do procedimento - é a necessidade de assegurar a liberdade das pessoas para que elas possam participar do procedimento. E, para que essa liberdade possa ser exercida em condições razoáveis, exige-se também um conjunto mínimo de condições materiais, como educação, alimentação etc" BARCELLOS, Ana Paula de. A eficácia jurídica dos princípios constitucionais: o princípio da dignidade da pessoa humana. 3. ed. Rio de Janeiro: Renovar, 2011, p. 174.

${ }^{2}$ HABERMAS, Jürgen. A inclusão do outro: estudos de teoria política. São Paulo: Edições Loyola, 2002, p. 310-311.

${ }^{3}$ BARCELLOS, op. cit., p. 175.

${ }^{4}$ ALVES, Alinne Cardim; FERNANDES Cassiane de Melo. Reconstruindo e reformulando a democracia. In: SIQUEIRA, Dirceu Pereira Siqueira; AMARAL, Sergio Tibiriça. Democracia, liberdade e justiça social: fundamentos para uma teoria jurídica do reconhecimento. Birigui: Boreal, 2015, p. 27.
} 
Esta pretendida promoção das condições hábeis a empenhar uma contribuição ativa no campo da efetivação do conjunto de direitos e liberdades cruciais, projeta o possível exercício destes na medida em que os coautores sociais os reconhecem mutuamente como legítimos e exequíveis. Observado ainda que, tendo em vista as políticas públicas se definirem por ações estatais destinadas à execução de programas governamentais, mediante a intervenção estatal na sociedade, com esteio em lei e observância dos princípios e valores cunhados, é indubitável que o assentamento de determinadas pretensões no corpo político de ação lhes atribui maior efetividade.

Não se trata apenas de pretensões materiais, mas também de demanda por reconhecimento e inclusão, reivindicações identitárias tanto individuais quanto oriundas de determinados setores sociais desfavorecidos, em cognição das característica e diferenças singulares dos grupos, ao fim também da igualdade de condições, e do livre desenvolvimento da personalidade ${ }^{5}$.

Emana, assim, o grande desafio de se conseguir desenvolver um sistema que a todos reconheça e viabilize participação ativa por meio de técnicas isonômicas e imparciais. Ora, o próprio princípio da maioria, utilizado em vários modelos estatais, encontra dificuldades ao fim de fomentar certos direitos fundamentais. De toda forma, utilizando este exemplo, a adoção do modelo de decisão por maioria, tido como garantia ao melhor interesse da sociedade, deve efetivamente garantir este interesse geral, e não meramente figurar como demagogia teórica.

Neste sentido, José Joaquim Gomes Canotilho afirma que: “o princípio maioritário não exclui, antes respeita, o <pensar de outra maneira>, o <pensamento alternativo>. Noutros termos: o princípio maioritário assenta politicamente num <relativismo pragmático> e não num $<$ fundamentalismo de maiorias $>$ " .

Além disso, obviamente, nenhuma técnica ou método pode ratificar imposições ou domínios autoritários de privação, até porque determinadas indisponibilidades não estão ao alcance de qualquer maioria ou governante, pois dizem respeito a todos e não apenas ao grupo de domínio, além de que, qualitativamente equipotentes, os interesses da maioria devem concorrer em pé de igualdade com o direito e interesses das minorias no âmbito da influência

\footnotetext{
${ }^{5}$ MADRUGA, Sidney. Pessoas com deficiência e direitos humanos: ótica da diferença e ações afirmativas. São Paulo: Saraiva, 2013, p. 129-130.

${ }^{6}$ CANOTILHO, José Joaquim Gomes. Direito constitucional e teoria da constituição. 7. ed. Coimbra: Edições Almedina, 19--, p. 330.
} 
nas ações estatais. Ainda, é de se ressaltar por imperativo que, diante os conflitos sociais, a fluidez e a dinamicidade social, bem como pela conceituação histórico-social da maioria, esta pode se (re)compor amanhã pelas minorias de hoje, alterando todo o quadro posto, e legitimando outro formalizado agrupamento de atores ao poder maior ${ }^{7}$.

Cabendo então primordialmente ao Estado garantir a inclusão e o reconhecimento social, ao passo que tanto é controlado quanto fomentado pela participação social ativa, fazem-se necessários mecanismos hábeis a permitir que a vontade de toda a sociedade seja percebida e considerada, bem como acolhida quando possível, em acordo a parâmetros razoáveis, imparciais e objetivos, seja no que tange à incorporação de políticas pública ou, principalmente, ao campo da elaboração legislativa ${ }^{8}$. Cabível o apontamento de José Afonso da Silva no sentido de que: "a lei é, assim, reconhecida como o instrumento institucional de maior relevância no controle social, já que também é um instrumento de dominação política, o que postula atuação e controle democráticos na sua elaboração e aplicação, para coibir abuso e autoritarismo",

Entretanto não se trata, por fim, da consolidação de um sistema assistencialista ao qual se reportam todas as mazelas sociais, mas da formação de um mecanismo complementar ao fim de, via posições ativas gerais de empenho e cooperação, se alcançar o efetivo exercício de direitos, o livre desenvolvimento da pessoa e de sua personalidade, bem como o respeito à dignidade humana, independentemente da origem ou posição de cada um dos beneficiados, em prol da realização e desenvolvimento não apenas de cada indivíduo, mas de toda uma comunidade deles.

\section{LEGISLAÇÃO E PRETENSÕES EVIDENCIADAS}

Na perspectiva ampla dos conformes doutrinários, a função legislativa é tida como abarcante de um variado complexo de atribuições, típicas ou atípicas, concebidas na competência do Poder Legislativo, composto então pela feitura de leis, resoluções e outros atos normativos, pelas atividades administrativas inerentes a seus próprios serviços, ou

\footnotetext{
${ }^{7}$ Em complemento, lembra-se com Bonifácio de Andrada que: “o partido político é um agregado, um conjunto de pessoas dominadas por valores sociais que entra em conflito com outro grupo ou grupos, decorrente de divergências, em torno do exercício do poder, do governo, do comando de determinada comunidade".

(ANDRADA, José Bonifácio Tamm. Parlamento brasileiro e sua crise no fim do século. Brasília: coordenação de publicações da câmara dos deputados, 1995, p. 84.)

${ }^{8}$ BUSSINGUER, Marcela de Azevedo. Política pública e inclusão social: o papel do direito do trabalho. São Paulo: LTR, 2013, p. 29.

${ }^{9}$ SILVA, José Afonso da. Processo constitucional de formação das leis. São Paulo: Malheiros, 2006, p. 32.
} 
projetado em razão dos vieses sancionador donde se destaca exemplificativamente o julgamento do Presidente da República e outras autoridades do Executivo, Judiciário e Ministério Público por crimes de responsabilidade, ou fiscalizatório de controle dos atos da Administração Pública no âmbito do Parlamento ${ }^{10}$.

Numa possível consideração mais específica, trata-se da função pela qual cabe aos órgãos legiferantes a incumbência da elaboração de normas geral e abstratamente direcionadas ao atendimento dos interesses globais da sociedade, notadamente para, em certa forma inovando o ordenamento, criar, promover ou extinguir direitos, deveres e parâmetros. Deve, para tanto, expressar a vontade geral e atender aos interesses plurais, equivalentemente ${ }^{11}$.

A legislação deve então representar anseios genéricos, identificando e expressando as tendências e demandas sociais em conformidade ao interesse coletivo imparcializado. É justamente na supremacia do interesse coletivo que a lei há de legitimamente se estear, afastando assim o arbítrio de determinados grupos dominantes porquanto terão de ser contidos pelas vontades gerais bem como pela esquematização de um sistema moderador, hábil à fiscalização e contenção de desvios.

É por conta da necessidade de se materializar a vontade geral das hodiernas sociedades amplas e complexas que emanam determinados mecanismos de patrocínio plural, no que se destaca a técnica da representação. Sobre esta, ensina Manoel Gonçalves Ferreira Filho que:

O caráter representativo da Câmara popular aparece na lição de Montesquieu como um imperativo da natureza das coisas. Ou seja, como já se sublinhou anteriormente, entendia ele que os homens, por serem livres, deveriam governar-se a si próprios, mais isso seria impossível nos grandes Estados e inconveniente nos pequenos, porque o povo não era capaz de debater os problemas que surgissem. Todavia, se falta ao povo essa capacidade, está ele perfeitamente apto a escolher representantes capazes de discuter les affaires ${ }^{12}$.

Todavia, é justamente pela representatividade que determinados interesses obtêm maior facilidade em, através de seus porta-vozes, transpor a vontade geral para, no campo político, corporativamente consolidar vantagens particulares de grupos restritos, em concernência aos interesses apenas dos representados eleitores do mandatário em determinada

\footnotetext{
${ }^{10}$ SERRANO, Pedro Estevam Alves Pinto. O desvio de poder na função legislativa. São Paulo: FTD, 1997, p. 10.

${ }^{11}$ Oportuna a seguinte ilustração trazida por Manoel Gonçalves Ferreira Filho: "La loi est l'expression de la volonté générale. Essa afirmação solene, que abre o art. $6^{\circ}$ da Declaração de 1789, é o feliz resumo da concepção sobre a lei, que vinga no século XVIII e inspira o processo legislativo típico dos regimes constitucionais pluralistas" (FERREIRA FILHO, Manoel Gonçalves. Do processo legislativo. São Paulo: Saraiva, 2002, p. 19.) ${ }^{12}$ Ibid., p. 63.
} 
circunscrição ou conjuntura. Atuação esta que, infelizmente, pode acabar rebaixando a nobre essência da lei aos vícios dos caprichos humanos, bem como prejudicando a composição igualitariamente somatória de interesses variados, e não homogêneos, na produção da vontade geral $^{13}$.

A própria ordenação histórica da formação do Poder Legislativo reflete os efeitos do seccionamento estamental, donde nobres representaram nobres e comuns representaram comuns, numa dualidade de Câmaras específicas que concebeu o bicameralismo. Distinção representativa esta que parece seguir enraizada enquanto, em verdade, considerado que o princípio da soberania nacional por qual se representa a Nação, e o princípio da soberania popular segundo o qual há representação de todo o povo, deveriam se desenvolver conjuntamente, haveria de decorrer, por corolário lógico, uma necessária unicidade de ação mesmo que de órgãos e instituições distintos ${ }^{14}$.

Reverbera como consequência que, a incapacidade de a representação tida como oficial cumprir adequadamente os interesses dos variados grupos sociais, especialmente sobre as intercorrências diárias que afetam a vida de todos, acaba por fomentar a atuação dos denominados grupos de pressão, detentores do sustento político ou econômico dos instrumentos de poder, que influenciam a particularização da lei como expressão predominante de suas vontades particulares ${ }^{15}$ sobrepondo-as ao imperativo da formação cooperativa, que deveria ser válido para todos. De toda forma, é cediça a existência de nítida relação umbilical entre a construção das leis e as ideologias políticas dominantes as quais podem ou não se identificar com as ideologias políticas residuais, representativas da maioria do povo ${ }^{16}$.

E, assim, figurando uma antítese entre a ideologia da classe detentora do poder e a da classe que demanda a transformação das posições e relações sociais, emergem lides ideológicas que, segundo José Afonso da Silva:

\footnotetext{
${ }^{13}$ FERREIRA FILHO, Manoel Gonçalves. Do processo legislativo. São Paulo: Saraiva, 2002. p. 14, 66, 79 e 95.

${ }^{14}$ SILVA, José Afonso da. Processo constitucional de formação das leis. São Paulo: Malheiros, 2006, p. 60.

${ }^{15}$ Completa a lição trazida por Bonifácio de Andrada o qual, analisando o sistema brasileiro, afirma que: "Os dois maiores problemas que dificultam a prática democrática entre nós, quando se trata da escolha de representantes do povo é a influência abusiva do poder econômico de um lado e em seguida a falta de autenticidade na representação política. Resulta daí a escolha de deputados que não têm vinculações e nem conhecimento maior das localidades em que são votados, não expressando a vontade do eleitorado que os escolheu por serem fruto da manipulação de lideranças, envolvidas pelo financiamento das campanhas ou por outras razões semelhantes. Temos assim, na hipótese, a influência do poder econômico e a inautenticidade da representação política” ANDRADA, José Bonifácio Tamm. Parlamento brasileiro e sua crise no fim do século. Brasília: coordenação de publicações da câmara dos deputados, 1995, p. 49.

${ }^{16}$ FERREIRA FILHO, op. cit., p. 94, 96, 97 e 129.
} 
[...] poderiam ser solucionada pelas vias legislativas: $1^{\circ}$ ) se os órgãos legislativos fossem imparciais, o que é impossível, pois constituem parte do poder; $2^{\circ}$ ) se se não tolhesse a parte titular da pretensão de participar amplamente no processo legislativo, mas isso também não acontece em regra, pois a parte renitente exerce a resistência a partir dos meios de composição dos órgãos legislativos, pelas distorções do sistema eleitoral ${ }^{17}$.

Por conseguinte, como efeito das soluções legislativas construídas, também as políticas públicas, especialmente as de fomento, acabam por vezes atendendo mais a interesses privados do que públicos, porque pautadas em bases eivadas de subjetivismo e ideologias de grupos determinados, e não por critérios técnicos objetivos e imparciais. Assim despende-se o orçamento público ao fim de objetivos particulares, em detrimento da satisfação pública que se haveria de esperar ${ }^{18}$.

Despontando, pois, consideração sobre os efeitos e elementos próprios da formação legislativa, interpretativamente não se confundem a norma e a lei propriamente dita, principalmente no que tange a seus efeitos jurídicos e à ponderação de que a lei geralmente reflete interferências do poder. Há de se acrescentar ainda que, na construção da norma jurídica há maior consideração interpretativa da essência dos valores e princípios que regem o ordenamento e as relações da sociedade para que, assim, e na melhor forma, corrijam-se desvirtuamentos. Acrescenta, José Afonso da Silva, que:

\begin{abstract}
A conduta do legislador tem como missão revelar, em preceitos genéricos, o Direito (fato, valor e norma), que, social e historicamente, a sociedade tem como tal. Ocorre que a norma de conduta, tida como justa, é um tanto imprecisa, podendo ser concebida segundo vias diversas [...]. O legislador autêntico conduz-se no mesmo sentido dos valores jurídicos (justiça, segurança, ordem e paz social), acrescentando, às normas difusas, o valor (também jurídico, porque bilateral), da certeza, para que prospere a ordem na realização dos negócios jurídicos ${ }^{19}$.
\end{abstract}

Deve o aplicador mandamental atuar sempre em diretriz de uma diminuição do presente distanciamento que paira entre os ideais modernos a que o ordenamento, em sua gênese, se propôs a cumprir, e a sua efetiva realização na atual prática legislativa, notadamente no que diz respeito à adequação fática, que reveste as ações com juridicidade e legitimidade. Ora, a aplicação dos textos legais não pode manter dissonâncias prejudiciais a

\footnotetext{
${ }^{17}$ SILVA, José Afonso da. Processo constitucional de formação das leis. São Paulo: Malheiros, 2006, p. 133.

${ }^{18}$ POTTUMATI, Eduardo Carlos; FERREIRA, Filipe Furtado. Políticas públicas de fomento: entre interesses públicos e interesses privados. RVMD, Brasília, v. 7, n. 2, p. 310-335, jul-dez, 2013.

${ }^{19}$ SILVA, op. cit., p. 20.
} 
legítimas pretensões e imperativos da ordem econômica, cultural, política e social, em sua generalidade ${ }^{20}$.

Em atuação paralelamente simultânea, nesta continua pretensão de aproximar o Direito sociocultural que considera os múltiplos campos formativos, ao Direito legislado que esteia o ordenamento positivado ${ }^{21}$, sobretudo no âmbito de uma mutação que contraponha a ordem jurídica formalmente estática e conservadora com a ordem jurídica progressista, cultural e materialmente dinâmica, num sentido de justiça social, os representantes de minorias devem buscar a elevação de sua força ativa na transmudação da ordem ${ }^{22}$.

Mas, observa-se que, geralmente, na circunstância de a minoria oposicionista iniciar a lei, com esperança de ver seus interesses acolhidos e de minorar o contraste ideológico do programa de governo investido, a maioria governamental procura obstar tais pretensões, negando aprovação ou desvirtuando referidas proposituras. Todavia, este modelo gerencial não perde toda sua validade, desde que as oposições ideológicas tenham força efetiva de influência e não figurem apenas como uma tapeação formalmente aceita ${ }^{23}$.

Ou seja, a legitimidade do plano de interesses que compõem as decisões estatais, para além de mero artificio que, através de determinadas técnicas, valida o atendimento dos interesses de algumas pessoas ou grupos determinados, detentores de um domínio real do poder, deve em verdade servir à tutela e fomento dos interesses de todos, e cada um, independentemente da posição política, ideológica, econômica ou social. Outrossim, não podem ser utilizados expedientes que apenas visam justificar omissões limitadoras de direitos e liberdades fundamentais, ao passo que a atuação protetiva deve então dotar-se de um viés ativo.

Nesta linha, ademais, também no campo das políticas públicas há de se pretender o fortalecimento das minorias no posicionamento do Estado, bem como a redefinição de alguns papéis deste, na finalidade de uma remodelagem que lhe torne mais hábil a desmantelar redes que atuam exclusivamente em razão de alguns interesses privados, para então conseguir promover os bens coletivos em prol do desenvolvimento tanto pessoal quanto global, bem como da devida transformação social. Pois, uma gestão efetiva, igualitária e justa, se perfaz

\footnotetext{
${ }^{20}$ BONAVIDES, Paulo. Curso de direito constitucional. 29. ed. São Paulo: Malheiros, 2014, p. 189.

${ }^{21}$ Assim confirma Pasquale Stanislao Mancini, com a afirmativa de que, ao invés de não se considerar elementos exteriores e interdisciplinares: "Pelo contrário, que se proclame mais uma vez a necessidade do harmônico acordo entre a moral, o Direito, a política e a economia social no estudo das leis que governam as convivências humanas” MANCINI, Pasquale Stanislao. Direito internacional. Ijuí-RS: Unijuí, 2003.

${ }^{22}$ SILVA, José Afonso da. Processo constitucional de formação das leis. São Paulo: Malheiros, 2006. p. 19.

${ }^{23}$ Ibid., p. 134-135.
} 
através de sua conformação às pretensões dos mais variados grupos, principalmente no que tange à multiplicidades das instituições políticas, econômicas e sociais ${ }^{24}$.

Enfim, por toda técnica ou sistema, a exemplo das maiorias eleitorais e da representatividade, é imperativa a real convergência dos programas governamentais à conjuntura geral, que legitimamente se compõe pela expressão de todos, adequando-se sempre a esta vontade geral, em sua pluralidade e dinâmica mutabilidade, ao invés de servir a interesses privados daqueles que manipulam as estruturas governamentais, principalmente as vais legislativas, em proveito próprio seu ou do grupo a que pertence.

\subsection{LEGITIMIDADE DE AÇÃO}

Apesar de caber certa discricionariedade à competência legiferante, donde o legislador, por meio de determinados critérios de valoração e diretrizes materiais, constitucional e internacionalmente determinadas, implicam-se vínculos imperativamente margeadores da relação meio-fim. Ainda que pretensamente revestida com um "manto da intangibilidade" sobre a margem de seus elementos subjetivos, obviamente não se pode aceitar ações arbitrárias ou desarrazoadas. Assim, cabe sancionamento ao desvio de poder legislativo $^{25}$, que, apesar de geralmente decorrer pela modalidade de desvio de finalidade por inadequação da competência investida, tem múltiplas formas, a exemplo do vício na interpretação da mens legis em que os meios e fins da lei serão tidos por inadequados a fins axiológicos soberanos ${ }^{26}$.

Esta correção tanto da essência formadora quanto da interpretação pragmática da lei remete-se também aos eventuais choques ou correspondências que se formam entre os interesses públicos e particulares. Ora, apresentam-se legítimos alguns contrapontos que acabam por culminar em determinada legislação um pouco mais propensa a certa posição, até porque, obviamente, não pode decorrer que um pretenso interesse público colida com o interesse de todo e cada membro da sociedade. Desta forma, em certa medida é legitima a relação entre determinados interesses privados e sua consideração como interesse público,

\footnotetext{
${ }^{24}$ BUSSINGUER, Marcela de Azevedo. Política pública e inclusão social: o papel do direito do trabalho. São Paulo: LTR, 2013, p. 41.

${ }^{25}$ Neste posicionamento, Pedro Estevam Alves Pinto Serrano aponta o seguinte: “já demos um norte certo à localização da possibilidade de ocorrência do excesso ou desvio de poder legislativo, quando enunciamos a respeito da discricionariedade legislativa" SERRANO, Pedro Estevam Alves Pinto. O desvio de poder na função legislativa. São Paulo: FTD, 1997, p. 77-78.

${ }^{26}$ Ibid., p. 88 e 137.
} 
quando tomada em benefício do quadro geral, enquanto o que não se pode admitir é uma supremacia ou exclusividade dos interesses privados de apenas alguns grupos invariavelmente direcionadores do Estado $^{27}$.

No entanto, ocupando a sociedade civil o espaço da formação de demandas que se dirigem ao campo político prestacional, quanto mais dilatado o contraste entre a quantidade e qualidade das pretensões sociais e a capacidade de as instituições fornecerem respostas suficientes e adequadas, maior será o patamar de "ingovernabilidade" da sociedade. Ademais, a própria manutenção do ordenamento se vincula às atuações do Poder na sua função, jurídica-social, de atendimento da sociedade ${ }^{28}$ em suas mais variadas e mutáveis demandas ${ }^{29}$.

Este direcionamento operacional não deve se ater a pressupostos ou elementos singulares de seus atores, mas sim às finalidades que refletirão na sociedade somo um todo. Até porque, decerto, não figura como requisito de sua formação certo nível de instrução social ou quaisquer qualidades pessoais mínimas, visto que, em verdade, a capacitação há de figurar como finalidade, e não seu pressuposto da atividade governamental, na qual há de caber representantes de todas as classes e instruções ${ }^{30}$. Nesta diretriz, José Afonso da Silva, ao tratar da denominada "democracia elitista", assim explana:

\begin{abstract}
Ora, em verdade, a tese inverte o problema, transformando, em pressupostos da democracia, situações que se devem ter como parte de seus objetivos: educação, nível de cultura, desenvolvimento, que envolva a melhoria de vida, aperfeiçoamento pessoal, enfim, tudo se amalgama pelo regime democrático. Não são pressupostos desta, mas objetivos. Só numa democracia pode o povo exigi-los e alcança-los ${ }^{31}$.
\end{abstract}

\footnotetext{
${ }^{27}$ POTTUMATI, Eduardo Carlos; FERREIRA, Filipe Furtado. Políticas públicas de fomento: entre interesses públicos e interesses privados. RVMD, Brasília, v. 7, n. 2, jul-dez, 2013, p. 326.

${ }^{28} \mathrm{Em}$ raciocínio semelhante, José Afonso da Silva afirma o seguinte: "mas essas normas escritas só adquirem juridicidade enquanto traduzem o Direito cultural. Quando seu conteúdo não coincide com o objeto que mencionam, deixam de ser jurídicas. Caem em desuso ou devem ser ab-rogadas. Se permanecem atuando, contra o Direito real, satisfazendo apenas o interesse de Poder, dominado por uma classe social, assegurando seus privilégios, então cessaram de ser jurídicas, por não postularem justiça, para serem meramente políticas, protecionistas" (SILVA, José Afonso da. Processo constitucional de formação das leis. São Paulo: Malheiros, 2006, p. 20. )

${ }^{29}$ BOBBIO, Norberto. Estado, governo e sociedade: fragmentos de um dicionário político. São Paulo: Paz e terra LTDA, 2017, p. 226-227.

${ }^{30}$ Exemplificativamente, colaciona-se a anotação feita por Bonifácio de Andrada no sentido de que: “o subdesenvolvimento é fator cultural que se mistura com as áreas e segmentos desenvolvidos e onde a presença das suas manifestações sabe influir em qualquer setor da sociedade. Imperioso se torna que o Sistema Eleitoral contenha mecanismo que assegure aos candidatos da classe média, aos homens capazes, mas não ricos, condições mínimas de disputa eleitoral para os postos representativos do Parlamento" (ANDRADA, José Bonifácio Tamm. Parlamento brasileiro e sua crise no fim do século. Brasília: coordenação de publicações da câmara dos deputados, 1995, p. 51.)

${ }^{31}$ SILVA, José Afonso da. Curso de direito constitucional positivo. 36. ed. rev. e atual. São Paulo: Malheiros, 2013, p. 130.
} 
Indubitável, ainda, que a efetividade de determinados elementos é que legitima o Estado, o poder, e a própria constituição, e não o contrário. A título de exemplo tem-se que, não são propriamente os direitos fundamentais que se legitimam com o ordenamento, mas o ordenamento que ganha efetiva legitimidade em função de realmente assegurar direitos fundamentais. Além do mais, pela própria questão principiológica, faz-se devida uma reciprocidade ao fim do desenvolvimento mútuo e, principalmente, da dignificação humana. Certeira a anotação de Paul-Eugéne Charbonneau de que: "em todo corpo social, o respeito pela pessoa é considerado como um pré-requisito da legitimidade de todo governo e a exigência de liberdade como um direito sagrado de todo ser humano ${ }^{32,}$.

E, não se trata apenas de assegurar liberdades subjetivas, que equiponderam as concorrências entre particulares, ou reivindicações de benefícios, outorgados a cidadãos vinculados a Estado de bem-estar social, mas também de uma acepção jurídicoprocedimental, pela qual a legitimidade governamental se esteia conjuntamente nas autonomias privada e pública, bem como na discussão dos múltiplos interesses pelos próprios envolvidos, direta ou indiretamente, pessoal ou representativamente ${ }^{33}$.

No próprio regime constitucional de produção das leis, para além de um mero curso de formalidades despropositadas e ineptas, tem-se um verdadeiro guia mandamental sobre a manifestação do princípio democrático e da garantia, pela representação, dos interesses tanto da minoria quanto da maioria, e até mesmo dos grupos sociais de pressão, desde que dotados de reivindicações e atuações legítimas. Certo que, a devida observância do procedimento, esteado pela efetiva manifestação da vontade popular, figura como condição essencial à constitucionalidade dos resultados de sua construção, ao mesmo passo em que, através da formação racional, consolida o próprio fomento do ser humano, em especial ao que toca à sua natureza política ${ }^{34}$ e individualizada ${ }^{35}$.

Contudo, em que pese seu reconhecimento como requisito e valor fundamental da ordem democrática, não se visualiza uma pragmática efetividade homogênea da garantia de

\footnotetext{
${ }^{32}$ CHARBONNEAU, Paul-Eugéne. Adolescência e liberdade. São Paulo: EPU (Editora Pedagógica e Universitária LTDA), 1980, p. 141.

${ }^{33}$ HABERMAS, Jürgen. A inclusão do outro: estudos de teoria política. São Paulo: Edições Loyola, 2002, p. 297.

${ }^{34}$ Em construção diversa, mas semelhante, Giorgio Agamben considera o que segue: "E somente uma reflexão que, acolhendo a sugestão de Foucault e Benjamin, interrogue tematicamente a relação entre vida nua e política que governa secretamente as ideologias da modernidade aparentemente mais distantes entre si poderá fazer sair o político de sua ocultação e, ao mesmo tempo, restituir o pensamento à sua vocação prática" AGAMBEN, Giorgio. Homo sacer o poder soberano e a vida nua. Belo Horizonte: UFMG, 2007, p. 12.

${ }^{35}$ SERRANO, Pedro Estevam Alves Pinto. O desvio de poder na função legislativa. São Paulo: FTD, 1997, p. 12.
} 
consolidação das razões e ideologias de certos grupos, principalmente por conta da grande interferência das desigualdades atuais, e de múltiplos outros fatores que resultam num deficiente ou restrito acesso à sua realização, para determinada parcela de indivíduos. Portanto, em que pesem as nobres concretizações teóricas, há no campo prático da normatividade mandamental um abismo na efetividade dos projetos assumidos.

Imperativo observar, no entanto, que as atividades institucionais se moldam pela interação das demandas da sociedade em contraponto aos recursos e estruturas disponíveis, tendo em vista que, os empenhos avocados não podem se dissociar das possibilidades do Estado, mas também não é permitido se apartar da realidade social, sob o risco de instaurar-se uma provável crise de legitimidade da própria formação governamental então constituída.

Em ponto complementar, ainda referente ao âmbito de vinculação do legislador aos direitos fundamentais, ecoa questionamento sobre a denominada inconstitucionalidade por omissão, decorrente da inércia (total ou parcial) do legislador ante imposições, mais ou menos concretas (finalidade ou programa), contidas em normas diretivas. Situação esta que se mostra ainda mais complexa diante o postulado, explícito no ordenamento pátrio, de uma aplicabilidade imediata que atine a todos os direitos fundamentais ${ }^{36}$.

Unindo tais pontos, tem-se que justamente com a viabilidade da equipotente participação ativa de todos os indivíduos componentes do Estado, tanto na gênese formadora de sua composição quanto nos resultados decisivos dos planos legislativos ou de políticas públicas, bem como em âmbito de ulterior acompanhamento fiscalizatório, é que as decisões governamentais mais se tornam dignificantes, alcançam legitimidade, estabilidade e, por conseguinte, refletem o melhor trato das relações de governança ${ }^{37}$, em combinação com as reais possibilidades estatais ${ }^{38}$.

\footnotetext{
${ }^{36}$ SARLET, Ingo Wolfgang. A eficácia dos direitos fundamentais: uma teoria geral dos direitos fundamentais na perspectiva constitucional. 12. ed. rev. atual. e ampl. Porto Alegre: Editora Livraria do Advogado, 2015, p. 386.

${ }^{37}$ Em complemento, com os dizeres de Norberto Bobbio, ressalta-se que: "estreitamente ligado ao tema da ingovernabilidade está o da legitimação: a ingovernabilidade gera crise de legitimidade. Também este tema pode ser traduzido nos termos da mesma dicotomia: as instituições representam o poder legítimo no sentido weberiano da palavra, isto é, o poder cujas decisões são aceitas e cumpridas na medida em que consideradas como emanadas de uma autoridade à qual se reconhece o direito de tomar decisões válidas para toda a coletividade" BOBBIO, Norberto. Estado, governo e sociedade: fragmentos de um dicionário político. São Paulo: Paz e terra LTDA, 2017, p. 46.

${ }^{38}$ É possível afirmar, então, que as instituições e práticas, reguladoras das interações sociais, se legitimam pela influência direta, no processo de tomada de decisões, de todas as pessoas, e não apenas dos decisores políticos representantes de alguns grupos específicos, ao fim maior de assim se assegurar regras justas, inclusivas e fomentadoras da pessoa como ser humano. ALVES, Alinne Cardim; FERNANDES Cassiane de Melo. Reconstruindo e reformulando a democracia. In: SIQUEIRA, Dirceu Pereira Siqueira; AMARAL, Sergio Ttibiriça. Democracia, liberdade e justiça social: fundamentos para uma teoria jurídica do reconhecimento. Birigui: Boreal, 2015, p. 34.
} 
Esclarecedores os dizeres de Alain Supiot, no que segue:

O poder precisa ser reconhecido para exercer-se duradouramente, sem o que se esgota depressa na violência e na morte. Daí a questão que sempre agitou os maiores juristas, de Bodin a Kelsen, e cuja atualidade nada desmente: o que é que distingue um governo de uma quadrilha de ladrões? Por mais diversas que sejam, as respostas dadas a essa questão levam sempre à ideia de Referência. Não reconhecemos o poder a não ser que ele se refira a um sentimento ao qual aderimos [...]. E é um dos recursos da técnica jurídica conferir ao poder uma razão e instalar, assim, o palco do poder sobre o tablado da legitimidade [...]. Um poder que só tem por si a força está privado de razão e o poder legítimo é, ao contrário, aquele que mostra uma razão na qual acreditamos ${ }^{39}$.

A ilegitimidade ou a ingovernabilidade evidentemente gera consequências drásticas, especialmente porque, submetendo-se a leis que não o representam e a um governo que não é resultado de elementos realmente condizentes à realidade nacional, bem como havendo de assistir seus próprios meios servirem a interesses particulares de outrem, os indivíduos terão tanto derruída sua esperança como serão afetados por sentimentos e privações negativas que em muito prejudicam a personalidade humana, numa profundidade que poderá causar efeitos irreversíveis ${ }^{40}$.

Neste cenário, privado de elementos que fomentariam sua própria existência digna, bem como assegurariam integra sua personalidade e identidade, o indivíduo atingido pela insuficiência de representação nas prestações do Estado pode acabar fundamentando-se noutra instituição ou ideologia, a exemplo das referências religiosas, étnicas, regionais, sectárias, entre outras. Daí emanam reivindicações identitárias que aceleram a desestabilização do Estado e, pior, abrem caminho a confrontos cruéis ${ }^{41}$.

Trata-se de expectação, mesmo que alternativa, por um arrimo inclusivo e desenvolvimentista que pretensamente sustém aqueles os quais, geralmente figurando na linha mais descreditada da pirâmide social, restam desapossados de certos direitos, liberdades e garantias. Bem como de uma via emancipadora pela qual tais indivíduos tanto conseguem monitorar, visando obstar a propensão dos representantes cederem a impulsos ou pressões ${ }^{42}$, quanto participar da concretização de atos que interferem em sua própria autonomia

\footnotetext{
${ }^{39}$ SUPIOT, Alain. Homo juridicus: ensaio sobre a função antropológica do direito. São Paulo: WMF Martins Fontes, 2007, p. 182.

${ }^{40}$ MANCINI, Pasquale Stanislao. Direito internacional. Ijuí-RS: Unijuí, 2003, p. 66.

${ }^{41}$ SUPIOT, op. cit., p. 194.

${ }^{42}$ Em perspectiva semelhante, José Afonso da Silva ilustra que: "na França, o bicameralismo foi deliberadamente estabelecido para ensejar o controle de uma Câmara Alta conservadora sobre legislação presumidamente precipitada, mal informada o radical da Câmara Popular". SILVA, José Afonso da. Processo constitucional de formação das leis. São Paulo: Malheiros, 2006, p. 60.
} 
formativa, em prol de uma cooperação reciprocamente fomentadora. Oportunas, em complemento, as observações de Amartya Sen no sentido de que:

Os indivíduos vivem e atuam em um mundo de instituições. Nossas oportunidades e perspectivas dependem crucialmente das instituições que existem e do modo como elas funcionam. Não só as instituições contribuem para nossas liberdades, como também seus papeis podem ser sensivelmente avaliados à luz de suas contribuições para nossa liberdade ${ }^{43}$.

Em compêndio, esta legitimidade advém da recíproca compreensão e a própria determinação universal de uma comunidade política soberana, em acordo ao espírito tanto de sua Constituição quanto da ordem internacional, no sentido de fazer cumprir os direitos fundamentais e demais liberdades e garantias, dentro de um quadro valorativo e principiológico, em razão da mantença hígida do ordenamento por meio da real viabilidade participativa de todos na formação das decisões estatais em prol da efetividade de elementos fundamentais ao desenvolvimento dos indivíduos e, por conseguinte, do Estado.

\section{INFLUÊNCIA NA FORMAÇÃO E DESENVOLVIMENTO DA PESSOA EM ÂMBITO SOCIAL}

As normas, por óbvio, visam a materialização de efeitos tangíveis, inclusive com esteio em eventual imposição judicialmente assegurada, e tanto mais ganham densidade e exequibilidade quanto se articulam a princípios e valores que verdadeiramente refletem a essência da sociedade como um coletivo de vidas que coexistem em dignidade. Assim, diminuindo a largueza dos comandos mais abstratos e subjetivos, as normativas concretas ampliam a força conotativa, e, portanto, a força implicativa e vinculadora dos mandamentos maiores.

Por conta de sua repercussão, as ações estatais devem, por todo seu corpo político, representar um governo que realmente sirva à sociedade, por meio de leis adequadas à realidade social, em prol da formação e desenvolvimento de todo indivíduo ${ }^{44}$. Nesta perspectiva, Jurgen Habermas explana que:

\footnotetext{
${ }^{43}$ SEN, Amartya. Desenvolvimento como liberdade. Tradução de Laura Teixeira Motta, Revisão técnica de Ricardo Doninelli Mendes. São Paulo: Companhia das Letras, 2010, p. 188.

${ }^{44} \mathrm{Na}$ mesma forma, Pedro Estevam Alves Pinto Serrano aponta que: "o relevo político da lei no mundo contemporâneo dispensa maiores comentários, tal a inserção do conceito em nossas instituições e em nossa vida”. (SERRANO, Pedro Estevam Alves Pinto. O desvio de poder na função legislativa. São Paulo: FTD, 1997, p. 11.)
} 
Quanto ao direito vigente, também ele precisa ser interpretado de maneira diversa em face de novas necessidades e situações de interesse. Essa disputa acerca da interpretação e imposição de reivindicações historicamente irresolvidas é uma luta por direitos legítimos, nos quais estão implicados agentes coletivos que se defendem contra a desconsideração de sua dignidade ${ }^{45}$.

Nesta forma, considerando que a autonomia referente à liberdade de escolha, bem como a afirmação social no viés de reconhecimento do indivíduo considerado no plano político-social, asseguram reais condições de desenvolvimento e digna vivência, é dever do Estado (principalmente os tidos Estados-Sociais) materializar determinadas prestações dentro de suas possibilidades, ao passo que, paralelamente, a prudência política também deve ser considerada no plano das capacidades de fomento e dos resultados alcançáveis, da proporcionalidade entre fins e meios, para uma efetiva realização prática dos elementos visados à digna e efetiva formação da pessoa.

Não obstante o confronto entre os deveres inerentes e a realidade material e orçamentária das instituições e entes federativos, é certo que as limitações decorridas na prática governamental, bem como a necessária consideração de cada direito, mesmo que fundamental, em acordo às suas próprias especificidades, não se pode desatender a um imperativo controle sobre as discricionariedades da ação estatal, que deve ser o mais rígido e intenso possível quando a prestação restringida liga-se ao mínimo existencial e à própria existência ou integridade da pessoa. Observado ainda que, idealisticamente, caberia assegurar a todos muito mais do que apenas o mínimo existencial, especialmente quanto aos compromissos normativamente assumidos ${ }^{46}$.

Isto pois, a visão hodierna acerca do papel do poder e da instituição estatal há de se direcionar à sua compreensão como um elemento influenciador das formas de vida sociais, o qual, econômica, cultural e biopoliticamente compenetra a vida humana, no âmbito da (co)existência social. Observado que, não obstante todo e cada ser humano, por sua própria essência, teoricamente possuir os mesmos potenciais ao desenvolvimento, em verdade este apenas se realiza efetivamente, no aspecto individual ou coletivo, na medida em que há elementos favoráveis à sua formação. Ou seja, é o Estado influindo na própria dignificação da

\footnotetext{
${ }^{45}$ HABERMAS, Jürgen. A inclusão do outro: estudos de teoria política. São Paulo: Edições Loyola, 2002, p. 230.

${ }^{46}$ Em complemento colaciona-se os seguintes ensinamentos de Ana Paula de Barcellos: "a classe política, de acordo com as propostas com fundamento nas quais se elegeu, tem compromissos muito mais abrangentes com o bem-estar da população e o desenvolvimento humano em geral, que poderão mesmo transformar-se em um compromisso jurídico, através da edição de leis e atos normativos sobre a matéria" (BARCELLOS, Ana Paula de. A eficácia jurídica dos princípios constitucionais: o princípio da dignidade da pessoa humana. 3 . ed. Rio de Janeiro: Renovar, 2011, p. 369. )
} 
pessoa que, dotada de valores inerentes a seu próprio espírito, demanda substratos materiais de prestação, que perpassam pelo campo do direito. Magistrais os dizeres de Jurgen Habermas, pois: "na medida em que o direito intervém em questões ético-políticas, ele toca a integridade das formas de vida dentro das quais está enfronhada a configuração pessoal de cada vida",47.

Aliás, até mesmo a denominada personalidade jurídica configura-se como uma qualidade concedida à pessoa pelo direito, o que traz por decorrência alguns efeitos essenciais à plena formação, desenvolvimento e dignificação da pessoa, notadamente no que toca ao rol do que tido como direito da personalidade. Além de, assim, situar o indivíduo em posição de vindicar certos bens ou prestações do Estado, que o integra a seu quadro concretizador de direitos e garantias, e não de outra instituição ${ }^{48}$.

Ora, pela própria essência dos direitos fundamentais, aqui englobados os direcionados à personalidade, é certeira a característica da exigibilidade, que possibilita ao titular, ser humano reconhecido, uma postulação frente ao Estado-Administração e à sociedade a quem, principalmente por meio do Direito, cabe garantir a base de elementos essenciais, como a identidade, estado, e dignidade dos indivíduos, protegendo-os como pessoa a partir da devida tutela e satisfação de pretensões legítimas. Trata-se de integralmente amparar a pessoa socialmente reconhecida e individualizada, inclusive e em especial quanto à construção dos próprios pontos que envolvem sua formação e desenvolvimento, no que se destaca o papel dos instrumentos vinculadores do Estado, como as ordens legislativas, e da própria sociedade em cooperação e reconhecimento mútuo de seus integrantes ${ }^{49}$.

Até porque, a formação individual, que reflete na coletiva, depende do reconhecimento social e da participação política ativa, visto que, necessitando de condições viabilizadoras, apenas consegue cada pessoa realizar suas pretensões enquanto têm voz ativa junto àqueles que determinam práticas e ações as quais asseguram a materialização de substratos essenciais ao seu próprio desenvolvimento. Ou seja, há de considerar-se o indivíduo como ente

\footnotetext{
${ }^{47}$ HABERMAS, Jürgen. A inclusão do outro: estudos de teoria política. São Paulo: Edições Loyola, 2002, p. 165.

${ }^{48} \mathrm{Na}$ mesma linha Jurgen Habermas afirma que: "Não se pode permitir que o "lastro afiançador" seja transferido de âmbitos da formação política da vontade para substratos pré-políticos previamente dados, porque o Estado constitucional garante que ele mesmo - nas formas juridicamente abstratas do compartilhamento político e do status dos cidadãos ampliado de forma substancial por via democrática - assegura obrigatoriamente a integração social" (Ibid., p. 82)

${ }^{49}$ Nesta forma bem explana Jurgen Habermas que: "pelo fato de as pessoas só se poderem individuar pela via da socialização, a liberdade de um indivíduo une-se à de todos os outros, e não apenas de maneira negativa, por meio de limitações mútuas. Delimitações corretas, mais que isso, são o resultado de uma autolegislação exercida em conjunto. Em uma associação de livres e iguais, todos precisam entender-se, em conjunto, como autores das leis às quais se sentem individualmente vinculados como seus destinatários". (Ibid., p. 1)
} 
apresentado, reconhecido, representado e ativo na formação dos elementos sociais que o formam. Nesta esteira, a consideração de Giorgio Agamben de que:

\begin{abstract}
Dir-se-á, assim, que um termo pertence a uma situação se ele é apresentado e contado como unidade nesta situação (em termo políticos, os indivíduos singulares enquanto pertencem a uma sociedade). Dir-se-á, por sua vez, que um termo está incluído em uma situação, se é representado na metaestrutura (o Estado) em que a estrutura da situação é por sua vez contada como unidade (os indivíduos, enquanto recodificados pelo Estado em classes, por exemplo, como "eleitores") $)^{50}$.
\end{abstract}

Cabe, como ponto central, garantir a todos um quadro de equipolentes capacidades e liberdades para que, com estas, realmente possam exercer poder de decisão sobre sua própria forma vivencial, especialmente no campo da personalidade, donde se destaca a influência na práxis legislativa direcionadora da ação estatal. Ora, conforme ressalta Sidney Madruga: “sem condições que ponham em prática (políticas de igualdade, v.g., que concretam direitos sociais, econômicos e culturais) as liberdades individuais (os direitos civis e políticos), nem aquelas e nem estas encontrarão lugar neste mundo" ${ }^{, 51}$.

Pois a negativa ou insuficiência no reconhecimento ou consideração social, que priva o indivíduo de suas essencialidades e o toma pelo sentimento da falta de pertença a uma comunidade e da incapacidade de autodeterminação, além de prejudicar sua própria subsistência social, coloca-o em situação de extrema vulnerabilidade, o que facilita sua sujeição a múltiplas ações ofensivas e derruidoras de sua própria personalidade ${ }^{52}$. Nesta feita, uma digna coexistência vivencial em sociedade, portanto, há de assegurar que indivíduos se dotem de liberdade e igualdade suficientes para, de fato, usufruir direitos e formar personalidade em acordo aos valores escolhidos por si, livres de coações ou privações autoritárias, com a condicionante de enquadrar suas condutas no panorama ético-valorativo da sociedade, em prol de uma geral proteção humana.

\footnotetext{
${ }^{50}$ AGAMBEN, Giorgio. Homo sacer o poder soberano e a vida nua. Belo Horizonte: UFMG, 2007, p. 31.

${ }^{51}$ MADRUGA, Sidney. Pessoas com deficiência e direitos humanos: ótica da diferença e ações afirmativas. São Paulo: Saraiva, 2013, p. 89.

${ }^{52}$ Em critério argumentativo semelhante, Hannah Arendt lembra que: "viver uma vida inteiramente privada significa, acima de tudo, estar privado de coisas essenciais a uma vida inteiramente humana: estar privado da realidade que advém do fato de ser visto e ouvido por outros, privado de uma relação "objetiva" com eles decorrente do fato de ligar-se e separar-se deles mediante um mundo comum de coisas, e privado da possibilidade de realizar algo mais permanente que a própria vida. A privação da privatividade reside na ausência de outros; para estes, o homem privado não aparece, e, portanto, é como se não existisse. O que quer que ele faça permanece sem importância ou consequência para os outros, e o que tem importância para ele é desprovido de interesse para os outros". (ARENDT, Hannah. A condição humana. Tradução de Roberto Raposo. 12. ed. rev. Rio de Janeiro: Forense universitária, 2014, p. 72.)
} 
Mas, apesar da intenção de fomentar garantias jurídico-legais que vinculem o Estado à tutela da vida humana e garantam autonomia ao indivíduo, no processo de subjetivação que o leva a racionalmente desenvolver sua própria personalidade, bem como uma preocupação social pela participação pública na (re)construção de sociedades que não mais sejam marcadas por desigualdades, econômica, política e social, ou outras circunstâncias derruidoras da essência humana, em verdade não se pode integralmente suster nas normas jurídicas a função de solucionar todas as dificuldades e inconstâncias sociais, mas sim de afirmar sua estrutura como primordial à redução de desigualdades e à melhoria da conjuntura hodierna, especialmente no que toca ao direcionamento das atividades e orçamentos estatais a setores desfavorecidos.

No rol de soluções desejáveis, Denise Vital e Silva e Rodrigo Felberg apontam a necessidade:

[...] de ampliação dos espaços democráticos nas decisões políticoestatais e nos resultados do processo econômico (internalizando-se os centros de decisão econômica, ainda que por interveniência estatal) como uma forma de reversão da concentração de renda, impedindo ou, pelo menos, dificultando a dinâmica desenfreada de disparidades sociais e regionais; de adoção e de incrementação de políticas governamentais; de criação de empregos e de geração de rendas; enfim, de tudo o que possa também propiciar um equilíbrio no desenvolvimento econômico e social de nosso país ${ }^{53}$.

Enfim, almeja-se uma formação que vise, ante a figuração do ser humano no cerne estruturante de nossa sociedade e ordenamento, primordialmente a consolidação de oportunidades capacitantes e fomentadoras de cada indivíduo como pessoa livre e capaz a desenvolver e formar sua própria personalidade, e que assim viva dignamente e usufrua de todos os direitos mais caros ao ser humano. Até porque, a partir de condições apropriadas e do afastamento das principais fontes de privação das liberdades, tanto os indivíduos em suas particularidades quanto a sociedade como um todo conseguem efetivamente modelar seus destinos através dos comportamentos escolhidos, e da cooperação entre uns e outros, para o real alcance do tão almejado desenvolvimento geral, em prol do atendimento de toda a sociedade em suas legítimas pretensões.

\footnotetext{
${ }^{53}$ SILVA, Denise Vital; FELBERG, Rodrigo. Reintegração social e trabalho dos cidadãos-egressos. In: SMANIO, Gianpaolo Poggio; BERTOLIN, Patrícia Tuma Martins; BRASIL, Patrícia Cristina (org.). O direito na fronteira das políticas públicas. São Paulo: Ed. Páginas e letras, 2015, p. 29.
} 


\section{CONCLUSÃO}

Tomando por base a generalidade das sociedades hodiernas em que, tão complexas e plurais, emanam inúmeros interesses e demandas das mais variadas origens e projeções, bem como que determinadas técnicas de decisão configuram o itinerário de direcionamento das atuações humanas, deve-se atentar que, além do bom convívio social, fomento da pessoa humana e configuração de uma sociedade mais justa e igualitária, também o sistema apenas será legitimo se realmente visar o interesse social geral considerando a multiplicidade social, em diálogo aberto, para satisfazer não apenas as maiorias, mas todos os indivíduos, na maior medida em que se faça possível assegurar a todos a realização de direitos fundamentais, tanto em prol do alcance da própria legitimidade governamental quanto ao desenvolver dos indivíduos e da sociedade como um todo.

Ou seja, simultaneamente à consideração da pessoa como fim maior do ordenamento, pauta-se a legitimação do sistema governamental, em especial ao campo de sua função legislativa, enquanto reconhecidos todos os indivíduos como sujeitos ativos do poder político, independentemente de comporem a maioria ou minoria divisional. Configura-se, portanto, uma face biopolítica do Estado, em que tanto exerce influência profunda na possibilidade de formação da personalidade do indivíduo, quanto tem sua existência garantida pelos reflexos da satisfação humana.

Outrossim, quanto mais assegurados pressupostos básicos da concepção dignificadora da pessoa e maior o respeito aos direitos humanos, menor parece ser, em proporção oposta, a probabilidade de haver graves crises institucionais. Deve-se, portanto, em prol da higidez do indivíduo e da sociedade, prover os meios materiais efetivamente concretizadores dos mandamentos mais nobres e valiosos à digna (co)existência humana, bem como ao protagonismo do indivíduo na formação de conjuntura mais justa e dignificante.

A efetividade do direito de participação das pessoas nas definições normativas, aciona a função estatal de propiciar instrumentos primordiais ao desenvolvimento da pessoa em toda sua extensão, por via de mecanismos aptos a permitir seja sua vontade ouvida e acolhida, dentro do que possível, tanto em âmbito das formulações legislativas quanto da incorporação de políticas públicas, a elas vinculadas. E, levando em conta a fundamentalidade material de tais políticas, ante as necessidades que embasam as relações jurídico-sociais elementares à (co)existência digna, desponta o dever do Estado atuar primordialmente na tutela e fomento de certas coletividades desamparadas, visto que esta conjuntura transcende a esfera privada ao 
refletir em corolários expressivos no cenário público. Ademais, por sua intima relação, não há efetivamente direito se não garantidas liberdades subjetivas essenciais, e tampouco há Estado legítimo se não respeitada toda e qualquer pessoa que autenticamente figure em seu quadro de ação.

Ainda, não há direito sem conformidade à realidade social, pois a missão principal deste, paralelamente ao incremento da vivência da pessoa, é justamente a busca por transformação social, sob pena de grave crise substancial. E nesta perspectiva, figurando como norte disciplinador da vida em sociedade e alicerce assegurador de elementos componentes da personalidade e dignidade humana, tanto numa perspectiva individual quanto social, é imperativo que, objetivando a construção de um mundo melhor e mais justo, haja uma mais equânime distribuição de recursos e ferramentas de participação social nas decisões estatais, bem como a eliminação das múltiplas exclusões que afetam alguns seres humanos

\section{REFERÊNCIAS}

AGAMBEN, Giorgio. Homo sacer o poder soberano e a vida nua. Belo Horizonte: UFMG, 2007.

ALVES, Alinne Cardim; FERNANDES Cassiane de Melo. Reconstruindo e reformulando a democracia. In: SIQUEIRA, Dirceu Pereira Siqueira; AMARAL, Sergio Ttibiriça. Democracia, liberdade e justiça social: fundamentos para uma teoria jurídica do reconhecimento. Birigui: Boreal, 2015.

ANDRADA, José Bonifácio Tamm. Parlamento brasileiro e sua crise no fim do século. Brasília: coordenação de publicações da câmara dos deputados, 1995.

ARENDT, Hannah. A condição humana. Tradução de Roberto Raposo. 12. ed. rev. Rio de Janeiro: Forense universitária, 2014.

BARCELLOS, Ana Paula de. A eficácia jurídica dos princípios constitucionais: o princípio da dignidade da pessoa humana. 3. ed. Rio de Janeiro: Renovar, 2011.

BOBBIO, Norberto. Estado, governo e sociedade: fragmentos de um dicionário político. São Paulo: Paz e terra LTDA, 2017.

BONAVIDES, Paulo. Curso de direito constitucional. 29. ed. São Paulo: Malheiros, 2014.

BUSSINGUER, Marcela de Azevedo. Politica pública e inclusão social: o papel do direito do trabalho. São Paulo: LTR, 2013. 
CANOTILHO, José Joaquim Gomes. Direito constitucional e teoria da constituição. 7. ed. Coimbra: Edições Almedina, 19--.

CHARBONNEAU, Paul-Eugéne. Adolescência e liberdade. São Paulo: EPU (Editora Pedagógica e Universitária LTDA), 1980.

FERREIRA FILHO, Manoel Gonçalves. Do processo legislativo. São Paulo: Saraiva, 2002.

HABERMAS, Jürgen. $A$ inclusão do outro: estudos de teoria política. São Paulo: Edições Loyola, 2002.

MANCINI, Pasquale Stanislao. Direito internacional. Ijuí-RS: Unijuí, 2003.

MADRUGA, Sidney. Pessoas com deficiência e direitos humanos: ótica da diferença e ações afirmativas. São Paulo: Saraiva, 2013.

POTTUMATI, Eduardo Carlos; FERREIRA, Filipe Furtado. Políticas públicas de fomento: entre interesses públicos e interesses privados. RVMD, Brasília, v. 7, n. 2, p. 310-335, jul-dez, 2013.

SARLET, Ingo Wolfgang. A eficácia dos direitos fundamentais: uma teoria geral dos direitos fundamentais na perspectiva constitucional. 12. ed. rev. atual. e ampl. Porto Alegre: Editora Livraria do Advogado, 2015.

SEN, Amartya. Desenvolvimento como liberdade. Tradução de Laura Teixeira Motta, Revisão técnica de Ricardo Doninelli Mendes. São Paulo: Companhia das Letras, 2010.

SILVA, José Afonso da. Processo constitucional de formação das leis. São Paulo: Malheiros, 2006.

SILVA, José Afonso da. Curso de direito constitucional positivo. 36. ed. rev. e atual. São Paulo: Malheiros, 2013.

SILVA, Denise Vital; FELBERG, Rodrigo. Reintegração social e trabalho dos cidadãosegressos. In: SMANIO, Gianpaolo Poggio; BERTOLIN, Patrícia Tuma Martins; BRASIL, Patrícia Cristina (org.). O direito na fronteira das políticas públicas. São Paulo: Ed. Páginas e letras, 2015.

SERRANO, Pedro Estevam Alves Pinto. O desvio de poder na função legislativa. São Paulo: FTD, 1997.

SUPIOT, Alain. Homo juridicus: ensaio sobre a função antropológica do direito. São Paulo: WMF Martins Fontes, 2007. 


\section{DADOS DA PUBLICAÇÃO}

Categoria: artigo submetido ao double-blind review.

Recebido em: 18/06/2018.

Aceito em: 31/12/2019. 
